\title{
Tornar-se Pai e Mãe em um Processo de Adoção Tardia
}

\author{
Becoming Father and Mother in a Late Adoption Process
}

\author{
Nina Rosa do Amaral Costa* \& Maria Clotilde Rossetti-Ferreira \\ Universidade de São Paulo, Ribeirão Preto, Brasil
}

\begin{abstract}
Resumo
Assistimos surgir no Brasil uma nova cultura de adoção que busca famílias para crianças e não crianças para famílias. Essa proposta comporta um novo projeto de família, de maternidade e paternidade, atribuindo novos sentidos ao ser pai e mãe, distinto do tradicional modelo associado à consanguiinidade. A adoção tardia inserese nesse novo contexto. Para compreender os processos de construção de maternidade e paternidade nessas circunstâncias, é importante investigar as significações produzidas pelo casal ao tornar-se pai/mãe. Este artigo foca a produção discursiva de um casal durante entrevistas domiciliares, realizadas no decorrer do processo de adoção tardia de duas irmãs (4 e 5 anos). São apresentados os sentidos produzidos na conversação, em resposta à pergunta sobre como era ser pai ou ser mãe naquele momento. A análise aponta especificidades do tornar-se pai/mãe por adoção tardia, a difícil e frágil construção de vínculos e a necessidade de acompanhamentos pós-adotivos.

Palavras-chaves: Adoção; maternidade; paternidade; rede de significações; práticas discursivas.
\end{abstract}

\begin{abstract}
A new culture of adoption emerges in Brazil, which searches a family for a child, instead of a child for a family. This proposal holds new family, maternity and paternity projects. In it, new meanings are attributed to being father and mother, distinct from the traditional consanguinity model. Late adoptions are clearly inserted in this context. To understand the processes of building adoptive motherhood and fatherhood in those circumstances, it is important to investigate the meanings produced while becoming father/mother. This paper focuses on the discursive production of a couple when interviewed at home, during the late adoption process of two sisters ( 4 and 5y.o.). The meanings produced in the conversation are presented, on answering the question on how it was to be father or mother at that moment. The analysis points towards the specificities of becoming father/mother during late adoption, the difficult and fragile construction of bonds and the need for post-adoptive support.

Keywords: Adoption; motherhood; fatherhood; network of meanings; discursive practices.
\end{abstract}

A prática da adoção tem integrado as sociedades humanas há muito tempo. As mais antigas civilizações que conhecemos contemplam alguma regulamentação de situações de adoção que atendiam a diferentes propósitos, como a escolha de Faraós no Egito e o fortalecimento de alianças na criação de linhagens hereditárias mais convenientes em Roma. Tais regulamentações foram encontradas no Egito, Índia, China, Grécia e Roma, sendo a mais antiga presente no Código de Hammurabi (2800 a.C.). Desse modo, parece razoável afirmar que não houve nenhuma época histórica sem alguma prática relativa à adoção (Brodzinsky, Smith \& Brodzinsky, 1998; Palacios, Sandoval \& Espinosa, 1996).

Entretanto, se as significações sobre adoção, suas práticas e regulamentações legais sofreram inúmeras mudanças ao longo da história, elas sempre atenderam aos inte-

\footnotetext{
* Endereço para correspondência: Universidade de São Paulo, Faculdade de Filosofia, Ciências e Letras de Ribeirão Preto, Depto. de Psicologia e Educação (CINDEDI), Av. Bandeirantes, 3900, Monte Alegre, Ribeirão Preto, SP, 14040-901. Tel.: (016) 36023791; Fax: (016) 3633-5668. E-mail das autoras:ninarosa@usp.br; mcrferre@usp.br Agradecimentos à FAPESP e CNPq
}

resses dos adultos e das sociedades, sendo as necessidades das crianças pouco consideradas. Por isso, podemos afirmar que vivemos de algumas décadas para cá um processo novo. Uma era marcada pelo melhor interesse da criança, filosofia internacional que norteia as regulamentações e políticas de atenção à criança em vários países (Palacios \& Amorós, 2006).

A partir dessa perspectiva, vimos surgir no Brasil um movimento por uma nova cultura de adoção, a qual preconiza que se deve buscar uma família para uma criança e não uma criança para uma família. Com o apoio de organizações sociais e de técnicos do judiciário, essa nova cultura da adoção busca fomentar adoções diferenciadas, chamadas adoções modernas, como as adoções tardias, de grupos de irmãos, de crianças com necessidades especiais, portadoras do vírus HIV e as adoções inter-raciais (Freire, 2001). No entanto, essa nova cultura da adoção comporta um novo projeto de família, de maternidade e de paternidade e atribui novos sentidos ao ser pai e mãe. Pressupõe uma família que aceite o diferente, a alteridade, que não só lide com projetos de filiação alternativos, mas que efetivamente adote o diferente. Como homens e mulheres se tornam pais e mães nestas circunstâncias? 
Nesse sentido, apresentamos neste artigo parte da pesquisa de doutorado de uma das autoras, a qual buscou investigar a produção de sentidos relacionados à maternidade e paternidade por casais, no momento em que se tornaram pais e mães por meio de uma adoção.

\section{O Melhor Interesse da Criança}

Brodzinsky, Lang e Smith (1995) argumentam que, se no passado a adoção foi vista como um meio de legitimar necessidades específicas dos adultos ou necessidades das sociedades, atualmente o foco principal mudou. Embora muitos ainda achem que a adoção serve para solucionar o problema dos casais inférteis, para os autores, nos EUA, o foco principal se fundamenta no melhor interesse da criança.

Palacios e Amorós (2006) também argumentam que a adoção e o acolhimento na Espanha mudaram, passando a ter um maior número de adoções internacionais e de crianças acima de sete anos, ou com necessidades especiais. Tais mudanças são o reflexo das modificações legislativas de 1987 e 1996 que passaram a priorizar o melhor interesse da criança; a focar que esses interesses devem ser providos por uma família e não por uma instituição; e que as decisões sobre medidas de proteção à criança precisam ser tomadas por uma equipe de profissionais (psicólogos e assistentes sociais), desvinculada do Judiciário. Para os autores, as mudanças sociais e legislativas formaram um panorama que favoreceu novas práticas de adoção e novas concepções de família adotiva.

No Brasil, as mudanças na legislação também promoveram novas práticas relacionadas à adoção. Em 1990, com a promulgação do Estatuto da Criança e do Adolescente (ECA), regido pela doutrina da proteção integral da criança e adolescente (que preconiza o melhor interesse da criança), ficaram estabelecidas diferentes possibilidades de adoção: a adoção unilateral ou monoparental (um dos cônjuges ou concubino adota o filho do companheiro); a adoção singular (pessoas solteiras, viúvas, separadas ou divorciadas); e a adoção conjunta feita por casais ou concubinos. Assim, qualquer pessoa maior de 21 anos pode adotar, independente do seu estado civil, desde que tenha 16 anos de diferença do adotado e não seja parente ascendente (avô ou avó) ou irmão. Isso torna o processo de adoção mais democrático e facilita a constituição de diferentes modelos de família, desde que sejam atendidos os interesses das crianças. Além disso, novos procedimentos foram adotados, como os candidatos à adoção precisarem se submeter a um processo de avaliação e seleção realizado por um corpo técnico (assistentes sociais e psicólogos) do Judiciário. O ECA ainda prevê um trabalho sistemático de acompanhamento e orientação da criança e da família em todo o processo de adoção.

Entretanto, se traçarmos um breve histórico da adoção no país, verificamos que o melhor interesse da criança não foi priorizado ao longo de muitos anos, o que dificulta a mudança de representações e significações atribuídas à adoção, à maternidade e paternidade adotiva, como também às crianças adotadas.
Em termos legais, por exemplo, embora a prática da adoção já existisse na família patriarcal colonial, onde conviviam filhos legítimos, ilegítimos e apadrinhados em diferentes formas de afiliação, adoção só aparecerá no Código Civil Brasileiro de 1917. Estabelecia-se nesse momento que só "maiores de cinqüenta anos, sem prole legítima ou legitimada, poderiam adotar" (Granato, 2003, p. 44). A adoção era revogável e não era vista como um modo normal de constituir família, sendo, de certa forma, desestimulada pela lei. Só quarenta anos depois (em 1957) houve mudanças na lei relativa à adoção, sendo reduzida a idade mínima dos adotantes de 50 para 30 anos (assim casais jovens podiam adotar), passando a diferença de idade exigida entre adotante e adotado a ser de 16 anos e podendo o adotado usar o nome dos adotantes. Entretanto, caso houvesse filhos legítimos, a adoção não envolvia direitos sucessórios.

Em 1965, com a criação da legitimação adotiva houve a exigência de um período de guarda de três anos antes de deferir a legitimação, que era irrevogável e previa o rompimento com a família de origem. Os adotantes podiam modificar nome e prenome da criança, mas, caso nascessem filhos legítimos, o adotado não tinha direitos sucessórios. Para adotar, era necessário um período de 5 anos de matrimônio sem filhos ou comprovação de esterilidade mediante laudo médico, para o casal ser dispensado desse período (Granato, 2003).

A Adoção Plena (onde há o corte de todos os laços com a família biológica e a emissão de um novo registro de nascimento) só acontece com o Código de Menores em 1979. Entretanto, ela só podia ser requerida para crianças menores de sete anos que estivessem em situação irregular, ou para aqueles acima dessa idade que já estivessem sob guarda dos adotantes. Pereira (1996) relata que a concepção vigente era de que o abandono material e moral do menor, fruto da situação irregular e desagregação de sua família, o levaria a uma marginalização mais ampla e seria um passo para a criminalidade. Essa era uma narrativa dominante sobre as crianças que necessitavam de medidas de proteção e sobre aquelas que poderiam ser adotadas. Com relação aos requisitos relativos aos adotantes, a idade mínima continuou sendo de 30 anos para um dos cônjuges, permanecendo também a exigência de cinco anos de matrimônio sem filhos, «que poderia ser dispensada na hipótese de esterilidade de um dos cônjuges, desde que provada a estabilidade conjugal» (Granato, 2003, p. 49).

É importante perceber como essas leis são o reflexo de concepções dominantes da sociedade sobre criança abandonada, adoção e família adotiva. Ao mesmo tempo, tais leis foram criando discursos normativos sobre adoção, maternidade, paternidade e família. Discursos que, até muito recentemente, conceberam a parentalidade por adoção como uma parentalidade de segunda categoria. Assim, embora as práticas de adoção sejam historicamente antigas, vivenciamos um momento novo (ao menos do ponto de vista legal), em que a criança está em foco e sendo proposta como sujeito de direitos. Entretanto, essa perspectiva se constitui em um desafio não apenas no âm- 
bito das políticas públicas para a infância, mas também no domínio privado, no âmbito das práticas em construção da maternagem e paternagem.

\section{Maternidade e Paternidade Adotivas}

No que se refere à maternidade e paternidade adotivas no Brasil, as pesquisas de Cassin (2000), Mariano (2004), Vargas (1998) e Weber (2003) apontam para a preferência brasileira pela adoção de recém-nascidos, de mesma cor de pele que a família adotante e, preferencialmente, do sexo feminino, visto que mulheres são representadas como mais dóceis e de fácil adaptação a novos ambientes. Essas pesquisas também revelam o medo da realização de adoções tardias. Medo fundamentado no estigma de que crianças mais velhas trariam consigo maus hábitos, defeitos de caráter adquiridos em suas famílias de origem (por convivência ou por herança biológica) ou ainda adquiridos em abrigos.

Trindade (1993), em uma pesquisa sobre as representações sociais da maternidade e paternidade, entre mulheres e homens que buscaram uma clínica de reprodução assistida, relata que entre as principais categorias definidoras da representação da maternidade encontram-se: (a) a identidade feminina: ser mãe como condição essencial para o ser mulher; (b) a realização pessoal: necessidade pessoal da maternidade como forma de realização; e (c) o filho biológico: só a presença de um filho biológico pode concretizar plenamente a maternidade. Com relação à paternidade, foram apontadas as mesmas categorias principais, o que além de indicar uma forte associação entre o ser mulher e ser homem com a necessidade de procriação, também aponta para a valorização do filho biológico em detrimento do adotivo.

A pesquisa de Weber (2003) possibilita traçar um perfil sobre adoção e família adotiva no Brasil. Ela trabalhou com uma amostra de 240 pais adotivos (recrutados em 105 cidades de 17 estados brasileiros), encontrando, dentre outros aspectos, que a principal motivação para adoção foi não ter filhos próprios (50\%), sendo que os pais adotivos entrevistados relatavam o desejo de seguir o padrão da biologia e passar pela experiência de cuidar de um bebê com poucos dias de vida. A maioria das crianças adotadas tinha até três meses de idade no momento da adoção $(71,4 \%)$.

Cassin (2000) descreve um perfil semelhante ao de Weber, ao fazer um levantamento de 502 pessoas que procuraram o Setor de Serviço Social e Psicologia da Vara de Infância e da Juventude da Comarca de Ribeirão Preto com intenção de adotar, entre 1986 e 1999. O autor apresenta que a maioria dos candidatos à adoção era casada ou amasiada (93,8\%); entre 30 e 39 anos; brancos; com ensino fundamental incompleto ou com ensino médio; e sem filhos (69,3\%). Quanto à criança que desejavam, 92\% queriam uma criança recém-nascida ou até um ano de idade; $47,3 \%$ não tinham preferência pelo sexo, mas dentre os que demonstram preferência, a maioria desejava menina; $89,7 \%$ desejavam uma criança branca; 92,7\% aceitavam somente uma criança saudável (apenas uma pessoa aceitava criança soropositiva ao HIV); e 57,5\% não adotariam irmãos.
Os dados da pesquisa de Mariano (2004), que analisou as peças processuais relativas à adoção no período entre 1991 a 2000 na Comarca de Ribeirão Preto, endossam o que foi apresentado por Cassin (2000), indicando a permanência do perfil dos adotantes e da criança desejada, mesmo dez anos após o ECA.

Com relação à adoção tardia, Ebrahim (2001) comparou pais que realizaram adoções de crianças maiores de 2 anos com pais que efetuaram adoções de bebês (adoções clássicas). A autora afirma que os adotantes tardios apresentam um nível sócio-econômico superior aos adotantes clássicos; estado civil mais diferenciado, o que significa a presença de adotantes solteiros, separados ou viúvos em contraposição à maioria absoluta de casados nas adoções de bebês; maior estabilidade e maturidade emocional; motivações mais altruístas para a adoção; além de uma maior presença de casais com filhos biológicos.

Vargas (1998), que acompanhou longitudinalmente famílias que fizeram adoções tardias, ressalta a importância de se buscar analisar o processo de adoção, inserido num contexto interacional que considere as questões dos pais e das crianças adotivas, visto que poucos trabalhos sobre adoção abordam os processos familiares.

Os estudos citados demonstram que as pessoas que buscam realizar adoções no Brasil estão for temente marcadas por concepções de maternidade, paternidade e família que valorizam o modelo biológico de parentalidade, os vínculos consangüíneos e de alguma forma procuram mimetizar essas relações através da adoção.

Gailey (2000), ao falar sobre as ideologias de maternidade e parentesco por adoção nos EUA, afirma que a adoção vem se tornando foco de muitas questões sobre maternidade, embora as famílias adotivas ainda representem uma pequena parcela da sociedade americana. A narrativa dominante sobre parentesco fundamenta-se na concepção de que este é mais forte onde há ligações genéticas entre pais e criança (blood is thicker than water), sendo a natureza mais for te que a criação (nature over nurture). A autora descreve que nos EUA, geralmente, uma mulher tenta todas as possibilidades de ter uma criança através de fertilizações assistidas, antes de resolver adotar. Frente a tal ideologia, a maternidade é significada como algo da natureza, sendo a adoção um estigma que une uma mãe ruim (incapaz de criar), com uma mulher ruim (incapaz de gerar). Além disso, há uma valoração de que na infância os laços maternos são mais fortes que os paternos por causa da gravidez e nascimento (birth bond), o que coloca o pai numa posição de desvantagem em relação à mãe. Para a autora, a adoção fornece uma lente através da qual podemos ver o parentesco sendo construído e não imposto, entendendo parentesco como um processo em que as pessoas vão se filiando a um grupo.

Wegar (1997), ao analisar as representações sobre a mãe adotiva e a mãe que entrega seu filho para adoção (birth mother) nos EUA, demonstra como a literatura clínica e científica sobre adoção tem refletido imagens normativas sobre maternidade, definindo-a prioritariamente em termos individuais ou biológicos, dando pouco ou nenhum relevo ao contexto cultural-econômico em que essa ma- 
ternidade ocorre. Nesses trabalhos, os insuficientes suportes econômicos e sociais destinados às mães que entregam seus filhos não ganham atenção, como também são negligenciadas as atitudes sociais frente à infertilidade e adoção que atingem a maternidade adotiva.

Alguns autores (Prynn, 2001; Rushton, 2003; Vargas, 1998; Weber, 2003) indicam a necessidade de mais estudos relativos à maternidade e paternidade em processos de adoção e de acompanhamento dos pais no processo de construção dessa parentalidade adotiva. Prynn (2001) argumenta que na Inglaterra a literatura sobre adoção está concentrada mais na criança do que nos pais adotivos, sendo necessários estudos que ouçam as experiências dos pais adotivos e descubram meios de dar suporte a esse tipo de parentalidade.

Dessa forma, endossamos a necessidade de pesquisas que favoreçam uma reflexão sobre maternidade e paternidade adotivas, que contemple o seu processo de construção, visto que poucos estudos investigam o tornar-se pai e mãe adotivos. Pensamos ser importante olhar para esse processo a partir das práticas discursivas dos envolvidos, onde múltiplos sentidos sobre o ser mãe e pai são produzidos e negociados, entendendo que ao chamar a atenção para a diversidade de sentidos produzidos na dinâmica das práticas discursivas e na dialogia das interações, mostramos parte de um processo de desenvolvimento ao tornar-se pai e mãe.

\section{A Construção do Corpus de Pesquisa}

$\mathrm{Na}$ construção do corpus de pesquisa, trabalhamos com o referencial teórico-metodológico da Rede de Significações (Rossetti-Ferreira, Amorim, Silva \& Carvalho, 2004), em interlocução com o referencial da produção de sentidos nas práticas discursivas (Spink, 1999). Tais referenciais exigem do pesquisador uma imersão no campo de estudo, em diferentes contextos relacionados à temática investigada. Dessa forma, o trabalho de campo ocorreu entre 2001 e 2003, período em que realizamos, além das visitas às casas dos casais participantes da pesquisa, entrevistas na Vara da Infância e da Juventude da Comarca de Ribeirão Preto (junto à equipe psicossocial), em um abrigo de crianças em um grupo de apoio à adoção como também participamos de encontros nacionais de grupos de apoio à adoção e de outros fóruns de discussões relativas à adoção e outras medidas de proteção.

Este artigo foca-se na produção discursiva de um casal, Marta e Cristiano (todos nomes apresentados são fictícios), acompanhado através de entrevistas abertas e domiciliares, ao longo do processo de adoção tardia de duas irmãs (Luciana e Cristina). O casal participou da pesquisa mediante a assinatura de um Termo de Consentimento Informado que, além de atender a requisitos éticos de pesquisa com seres humanos, introduzia o tema e propunha a realização de três entrevistas individuais (em diferentes momentos do processo de adoção) e a realização de um diário pessoal. Esse era um registro livre, onde poderiam ser escritas idéias, lembranças e acontecimentos que os participantes julgassem importantes no seu processo de construção de paternidade ou de maternidade.

O corpus empírico produzido com este casal, ao longo de 1 ano e 3 meses, é composto por 7 entrevistas (6 individuais e uma conjunta) gravadas em áudio e 2 diários pessoais dos participantes. O primeiro contato foi anterior à chegada das meninas à casa. A Tabela 1 apresenta alguns dados de caracterização sobre o casal e as crianças.

Tabela 1

Idade/ Escolaridade/ Profissão/Cor da Pele dos Participantes e Idade/Cor da Pele/Escolaridade das Crianças

\begin{tabular}{|c|c|c|c|c|c|}
\hline & Casal & & & Crianças & \\
\hline & $\begin{array}{c}\text { Mãe } \\
\text { (Marta) }\end{array}$ & $\begin{array}{l}\text { Pai } \\
\text { (Cristiano) }\end{array}$ & $\begin{array}{l}\text { Cristina } \\
\text { (adotiva) }\end{array}$ & $\begin{array}{l}\text { Luciana } \\
\text { (adotiva) }\end{array}$ & $\begin{array}{l}\text { Fernando } \\
\text { (biológico) }\end{array}$ \\
\hline $\begin{array}{l}\text { Idade na } 1^{\mathrm{a}} \text {. entrevista/ } \\
\text { idade na última entrevista }\end{array}$ & 32 anos/ 33 anos & 34 anos/ 35 anos & 4 anos/ 5 anos & 5 anos/ 6 anos & o / 6 meses \\
\hline Escolaridade & $2^{\circ}$ grau técnico & $2^{\circ}$ grau técnico & pré-escolar & pré-escolar & - \\
\hline Profissão & $\begin{array}{l}\text { Desenhista } \\
\text { (não está trabalhando) }\end{array}$ & $\begin{array}{l}\text { Técnico em } \\
\text { telecomunicações }\end{array}$ & - & - & - \\
\hline Cor da pele & branca & branca & parda & parda & branco \\
\hline
\end{tabular}

Na análise das entrevistas foram realizadas: transcrição integral; leitura exaustiva; mapeamento temático seqüencial; levantamento dos interlocutores; seleção dos trechos mais marcantes de produção e negociação de sentidos relacionados à maternidade e paternidade. Buscou-se dar visibilidade à processualidade desses sentidos produzidos, tanto ao longo de cada entrevista, como do tempo de acompanhamento do casal.

Como resultado da análise, foram verificados dois momentos diferenciados nas narrativas de Marta e Cristiano em torno da produção e negociação de sentidos relacionados à maternidade e paternidade: 
1. O primeiro momento, demarcado como o anterior à chegada das meninas, é sinalizado pela relação com uma criança imaginária. Momento em que Marta fala da hesitação em ser mãe, enquanto Cristiano posicionase como desejoso de ser pai. A história de infertilidade do casal emerge na fala de ambos ao justificarem a decisão pela adoção. A partir de então, eles mostram as re-significações que ocorreram da criança inicialmente desejada (um bebê feminino) até iniciarem o estágio de convivência com Luciana e Cristina.

2. O segundo momento, marcado pela chegada das filhas adotivas na casa e o acontecimento inesperado da gravidez e nascimento do filho Fernando, ou seja, pela presença de crianças concretas. Período de intensas mudanças das relações familiares, onde Marta e Cristiano falam de uma maternidade e paternidade construídas nas e através das relações com os filhos.

Os sentidos relacionados à maternidade e paternidade apresentados neste artigo referem-se a esse segundo momento das narrativas de Marta e Cristiano. Fizemos um recorte dos sentidos produzidos na conversação em resposta direta à pergunta sobre como era ser pai ou ser mãe naquele momento, pergunta que aconteceu em todas as entrevistas.

Consideramos que, apesar da singularidade de cada história pessoal de Marta e Cristiano, nelas é possível encontrar sentidos, eventos, significações que são compartilhados com outros, o que torna cada biografia inteligível para os demais. Essa singularidade acontece situada em tempo e espaços sociais, dentro de contextos partilhados, o que permite reconhecê-la como uma experiência cultural (Fonseca, 1999).

\section{Resultados e Discussão}

Sentidos Produzidos Relacionados à Maternidade (entrevistas com Marta)

$1^{\mathrm{a}}$. Entrevista (8 dias com as meninas) - Ser mãe é prazeroso, mas complicado. Sente-se testada.

$\mathrm{N}$ : Marta, e como é que está sendo pra você ser mãe? M: Ai... eu gosto de cuidar delas, sabe? É... mas num é fácil não. É que elas testa a gente, deixa a gente!! [riso] é complicado. Parece que num é assim um trabalho cansativo, desgastante, mas é. Isso aí é prazeroso você tá cuidando, tal. Ah... tô gostando ... Eu acho que o amor vai sendo uma conquista do dia-a-dia, né? . . Que a minha aceitação delas, a pequena num quer ir embora de jeito nenhum. Agora, a maior, se contraria ela, ela fica: 'Eu vou pra o abrigo. Eu quero ir embora. Eu não gosto mais dessa casa'. Aí, teve um dia que eu falei pra ela: 'Tá bom, eu vou falar pro seu pai te levar lá'. Aí ela falou: 'Não, mamãe. Eu estava brincando, eu não quero ir. Eu quero ficar aqui.' E ela falou isso pra mim todos os dias: 'Eu quero ir pra o abrigo.' Que ela é muito xereta, faz muita arte, num posso perder ela um segundo, que elas tá fazendo arte . . E aí, tem umas coisas que eu num gosto nelas ... corre para lá, corre pra cá, e elas vem em cima. Isso me deixa estressada.

Marta, quando questionada sobre como estava se sentindo como mãe nesse curto período com as meninas ( 8 dias), diz que gosta de cuidar delas, que é prazeroso, mas que ser mãe não é fácil, pelo contrário, é complicado. Embora traga sentidos valorizados por ela como prazerosos do ser-mãe (cuidar, aconchegar), sua ênfase neste momento está na dificuldade: sente-se invadida em seu espaço e tempo, testada e cansada. Acha que Luciana e Cristina pedem limites o tempo todo e estranha muito o comportamento agitado delas. Entretanto, esse teste não se refere somente à bagunça que elas fazem na casa, aos comportamentos que Marta não aprova ou à desobediência de algumas regras. Marta sente-se testada por Luciana, porque esta, quando contrariada, afirma querer voltar para o abrigo, destituindo-a da autoridade que a posição de mãe lhe confere na relação, assim como do seu papel de mãe. Luciana, embora a nomeie como mãe, nem sempre a posiciona e reconhece dessa forma.

Brodzinsky et al. (1998) e Vargas (1998), em seus trabalhos com crianças adotadas tardiamente, relatam que elas testam a aceitação dos pais adotivos, que precisam ser preparados para lidarem com essa situação, não entendendo isso como um ataque pessoal, rejeição ou desafio da criança, mas como parte do seu processo de adaptação a um novo contexto de relações.

Assim, esse sentido de que a maternidade é complicada parece ser uma significação forte, em torno da qual Marta vai constituindo sua maternidade, desde a experiência dos tratamentos de fertilização assistida. É complicada porque ela está se tornando mãe de duas crianças que já argumentam, negociam, aceitam ou discordam dela e que, além disso, têm uma história passada de vivência em outra família e abrigo. As meninas participam na negociação de um lugar para elas nessa família, co-construindo com Marta e Cristiano sentidos de maternidade, paternidade e família.

Durante essa primeira entrevista, Marta se refere à Luciana e à Cristina, principalmente, usando o plural as meninas ou ainda falando a maior ou a menor. Percebemos que Luciana e Cristina serão nomeadas aos poucos, ao longo do processo de adoção. Entretanto, Marta já começa a constituir diferentemente cada filha. Ela pontua as dificuldades que vê em Luciana, a mais velha, dando ênfase para falar dela, sobre os seus comportamentos. Já Cristina parece não estar em tanta evidência, nesse momento.

$2^{\mathrm{a}}$. Entrevista (5 meses com as meninas) - Ser mãe é visto como tranqüilo, mas ele ainda está se adaptando. Sente-se invadida e dependente.

$\mathrm{N}$ : Cinco meses de ser mãe. Como foi esse período pra você?

$\mathrm{M}$ : Ah, agora já tá tranqüilo. Mas no começo era complicado me adaptar, e elas também se adaptar ao ambiente. E aí chegar no meio termo, mas agora já tá 
mais tranqüilo e eu ainda... como que eu falo? [silêncio] Eu ainda sinto falta do meu espaço, ainda, entendeu? Porque eu sou muito... eu sempre fui muito individualista, muito reservada [riso] e com criança não tem muito jeito de ser ... Você vai no banheiro, eu falo pra elas: 'Vocês não vem atrás de mim, heim! E nem me chama!' Aí, eu acabei de entrar: 'Mamãe, mamãe!, aí é meio complicado ainda, mas eu vou me adaptando . . . estranhei também pela falta de... como que eu vou falar? Tudo que eu vou fazer eu dependo, aonde que elas vão tá, se eu posso levar, se vai dá pro Cristiano ficar com elas. Então eu dependo dele ... eu vou ter que me adaptar porque é só eu e ele aqui na cidade, não tem aonde deixar elas. Aonde que eu não puder levar eu não vou poder ir, se ele não puder ficar. Então, isso é meio complicado pra mim . . . eu sempre fiz as minhas coisas sozinha, apesar de tá casada.

Marta responde a pergunta sobre o ser mãe relatando que ainda se sente em adaptação. Tal posicionamento também é conferido pela situação do processo legal, visto que eles ainda se encontravam com a guarda provisória das meninas com vistas de renová-la, pois o processo de destituição do poder familiar ainda não fora concluído. A ênfase de Marta nessa entrevista, ao falar da maternidade, é na adaptação e no seu sentimento de invasão. Ela sente falta do seu espaço, que o ser-mãe parece lhe ter roubado. Em sua narrativa, maternidade está associada à perda de privacidade e independência.

As relações com o marido mudaram e Marta agora vivencia uma posição de dependência que a incomoda, pois embora casada, sempre teve uma vida independente. A maternidade não apenas mudou sua rotina, mas mudou seu posicionamento e status no casamento. Não é mais uma mulher independente. Ela optou por permanecer em casa para fazer a adaptação com as meninas, com isso mudou sua vida e, diferentemente de Cristiano, convive com elas o dia inteiro. Talvez por isso sinta falta do seu espaço, de um tempo para si, e o seu relato nesse aspecto não é diferente daquele de outras mulheres que passam pelo mesmo processo de tornar-se mãe.

M: Agora a gente já tem o nosso espaço [ela e o marido], que agora eu ponho elas pra dormir às oito, como eu tinha te falado ... já sobra espaço pra gente de tempo, dá pra gente conversar, porque antes eu punha elas lá pelas dez ... Mas mesmo assim você ainda tem uma invasão. Você fala pra elas não entrar, aí esse negócio é meio complicado! . . . Mas se eu não fizer esse espaço, aí a gente não vai ter paciência com elas e nem com o outro que vai nascer também. Porque você não tem vida própria, você tem filhos!

Aqui Marta demonstra sua necessidade de privacidade. Espaço e tempo, isso é o que ela pede nesse momento de adaptação. Passados cinco meses ela demonstra o quanto o processo é intenso ao exigir dela reposicionamentos em relação ao marido, às meninas, ao filho que está na barriga e aos planos futuros. $3^{\mathrm{a}}$. Entrevista (1 ano e um mês com as meninas) - Ser mãe é complicado, ao mesmo tempo prazeroso e trabalhoso. Exige renúncia.

N: Marta, hoje, como você me diria que é ser mãe?

M: Viche!! É complicado, viu! E ao mesmo tempo prazeroso, igual uma amiga minha veio aqui eu falei pra ela que falam muito que ser mãe é padecer no $\mathrm{Pa}$ raíso, eu falei pra ela 'num sei aonde que é esse Paraíso ainda!' [risada] . . . eu acho assim que a mãe, vamos falar na minha classe social, num sobra o tempo pra eu me cuidar, esse me faz falta sabe, eu num tenho tempo mesmo! Eu tenho que cuidar da casa, tenho que tá vigiando elas, é o nenê, é o marido, então ... sempre da mãe é segundo plano. A gente vai fazendo, é automático! Você vai fazendo né, pros filhos, pro marido.

Marta ao falar do ser mãe inicia com a mesma afirmação que usou nas outras entrevistas: é complicado! Maternidade para ela é algo complicado em todos momentos em que conversamos. Afirma, inicialmente, ser prazeroso, mas logo emergem sentidos relacionados a uma situação de renúncia de si, de padecimento, de ausência de tempo. Ela reforça o ser complicado, ao não identificar o tal Paraíso da maternidade, porque para uma mulher com a sua condição econômica e social, a maternidade significaria muito trabalho, abdicação de si mesma e de seus planos futuros e estar em segundo plano.

Em seqüência, conversando sobre o ser mãe e os sentidos que Marta vinha apresentando de renúncia e dedicação, foi lhe perguntado se nesse aspecto do cuidado ela via diferença entre filho adotivo e não adotivo. Entretanto, ela responde argumentando sobre uma outra diferença: aquela em termos de amor e vínculo.

M: Ai, diferença?? Eu acho que o da Cristina tá se aproximando do Fernando... O tanto que eu gosto dele eu gosto dela, mas da Luciana eu tenho dificuldades. Vendo o diferente, a diferença é enorme! ... depois que eu tive ele que eu senti realmente que é ser mãe! Mãe é acho que até... chega a doer o amor que a gente sente pelos filhos! É engraçado isso. E agora que ele tá crescendo e... a Cristina a gente tá se aproximando o amor dos dois, eu acho que eu gosto bem dela, agora da Luciana ainda tá longe ainda ... depois que ele nasceu, é como se ele fosse um estranho, mas aí em poucos dias foi virando uma coisa importante, entendeu? . . é uma coisa interessante é tão assim rápido, que adoção devia ser assim também: o amor nascer assim oh!

$\mathrm{Na}$ linha narrativa que Marta desenvolve, a maternidade biológica aparece como a verdadeira, ao afirmar que depois que teve Fernando sentiu o que é realmente ser mãe. O amor por Cristina está quase alcançando o mesmo sentido por Fernando, mas a diferença parece ser enorme em relação à Luciana. Entretanto, logo em seguida, esse sentido de naturalização do vínculo entre mãe e filho biológico parece ser rompido ou coexistir com outros sentidos. Marta reorganiza sua argumentação em torno da maternidade biológica relatando que Fernando, embora filho 
biológico, também passou por um processo de estranhamento inicial e por um rápido processo de adoção afetiva! Quando ele nasceu, em poucos dias, de estranho foi virando uma coisa importante. Ela conclui dizendo que, com a adoção, o amor também deveria vir assim, rapidamente.

Essa parece ser uma das dificuldades da adoção tardia: estabelecer uma relação de maternidade, de paternidade e de amor com crianças mais velhas. Pode-se pensar que nossos modos culturais de vivência de maternidade não favorecem muito isso, pois estamos acostumados a nos tornar pais e mães de bebês, prioritariamente. Além disso, outras questões merecem ser consideradas como a incompletude maturacional do bebê humano que ao exigir cuidados para sua sobrevivência, favorece uma rápida vinculação afetiva; ou ainda que, na adoção tardia, as crianças negociam também a afetividade e a construção de seu amor filial, posicionando-se nas relações de modo mais ativo que um bebê. A habilidade do uso da linguagem, a história pregressa vivida, mostram um outro ser que não é tão incompleto, exigindo diferentes modos de vincularse afetivamente.

\section{Sentidos Produzidos Relacionados à Paternidade (entrevistas com Cristiano)}

$1^{\mathrm{a}}$. Entrevista (15 dias com as meninas) - Ser pai, uma experiência diferente. Tensão entre ter que se adaptar e exercer a autoridade.

$\mathrm{N}$ : E agora como é que está sendo ser pai?

C: É, acho que cada dia tem sido uma experiência diferente, né? Quando a gente veio com elas, o primeiro dia... teve um detalhe dum ovo de páscoa. Comprei um ovo de páscoa pra elas e aí elas comeram metade. Aí a gente falou: 'Agora vocês vão jantar.' É, doce ilusão. [sorri] 'Agora vocês vão jantar, num vão comer mais.' Aí depois ela veio pegar o ovo de páscoa na geladeira. 'Não, eu quero comer ovo de páscoa'. Falei: 'Não, você não vai comer.' 'Não, eu vou.' 'Não, você num vai.' 'Não, vou.' E ela segurando de um lado e eu do outro. Imagina a cena. E eu já fiquei assim, né? Porque eu falei: 'Pô, mas já vai me questionar? Já vai desobedecer?' Foi um descuido, ela saiu com o ovo de páscoa na mão e foi lá pra fora com a meninada. Então, você vê até a respeito da educação você já tem na sua cabeça umas regras feitas. 'Ah, vai ser assim, vou fazer isso, vai fazer aquilo'. Só que depois, você vai vendo que tem que modificar bastante seus conceitos e... na verdade, ir se adaptando.

Cristiano, ao falar do ser-pai, nesse momento, traz para sua narrativa algumas situações do cotidiano com Luciana e Cristina. Afirma que tem sido uma experiência diferente, especialmente porque ele tem que se adaptar a uma situação nova, a uma paternidade em que ele pode ser contestado, em que ele tem que negociar regras que para ele já eram claras. Ele vivencia uma paternidade que exige mudanças de diversas ordens (mudanças na casa, em sua rotina, em suas concepções de paternidade, etc.).
Pode-se pensar que toda paternidade exige mudanças. Entretanto, o fato de Luciana e Cristina serem mais velhas e adotarem posicionamentos na interação com ele de não aceitação das regras, de contra-argumentação, faz com que ele se sinta testado, questionado em seu papel de pai. Ser questionado em sua autoridade é sentido por Cristiano como o seu limite, talvez por ser exatamente a autoridade um dos sentidos relacionados à paternidade que ele e Marta mais valorizam, em torno do qual ele constrói a sua paternidade.

Nesse processo de adaptação a uma paternidade diferente da imaginada, os momentos de tensão são muitos. Cristiano tem dúvidas se é rigoroso na relação com as meninas e, várias vezes, diz ficar sem saber o que fazer. Porém, frente à dificuldade em ser obedecido por Luciana e Cristina, ele endurece e, dentro da concepção que tem de paternidade, considera que cabe a ele, principalmente, impor limites e ser respeitado. Ser a autoridade.

C: . . . a gente chegou num ponto que, num vai ter como ficar conversando muito. Vai ter que fazer. Você vai lá e você já dá uma dura ... 'Vamos lá catar agora e é pra guardar.' Porque elas... num sei se tão pedindo limite ou se num tem o hábito? Talvez, né? Mas elas ficam a cada instante te pedindo um limite. Até essa semana eu comentei com a Marta: 'Ah, acho que de repente a gente tá sendo um tanto severo' Mas elas... é agitar demais! . . . vira e mexe, falei: 'Óh! não tão adotadas, tá? Acho que vocês tem que... ou vocês se adaptam aí, vão comer . . . Porque se vocês não tiverem gostando, tal, vamos voltar. Na hora que vocês quiserem a gente volta, devolve vocês, vocês ficam lá'. Cristiano negocia com as meninas sua paternidade. Nesse momento, a devolução aparece como uma ameaça ou como uma alternativa real de solução da tensão. Fica evidente a diferença de poderes que existe na relação. Se uma relação entre um adulto e uma criança, entre um pai e um filho, já é de alguma forma assimétrica em termos de poder, o período de guarda da adoção tardia parece trazer um componente a mais nessa diferença: a possibilidade real da devolução, ou seja, da ruptura.

\footnotetext{
$2^{\mathrm{a}}$. Entrevista (4 meses com as meninas) - Ser pai é estar presente, cuidar, encaminhar e ser enérgico, se preciso.

C:...quem tá presente, eu acho é o pai... pra conhecer coisas novas pra brincar, cuidar, pra ter esse tempo, esse contato e que no final, lá no fim, alguém que te mostrou um caminho reto. Um encaminhador. Eu acredito que é a soma aí disso tudo. Dum carinho, um afeto e, se for preciso um pouco de ser enérgico e, no final, você conseguiu ter um caráter. Eu acho que um pai seria isso? [fala do seu pai] Eu espero ser assim. Espero dar esse afeto, esse carinho pra elas e que elas amanhã tenham um bom caráter. Esse é o compromisso, né?

Cristiano ao responder sobre o ser pai, constrói sentidos de que paternidade é compromisso. Compromisso de brincar, cuidar, ter tempo. Compromisso de ser um encaminhador, de mostrar o caminho certo, dar bons exem-
} 
plos e de formar caráter. Ao falar de si como pai, traz a sua história vivida como filho e a figura de seu pai. Cristiano espera ser um orientador e formador de caráter como seu pai foi para ele, estando presente, usando de autoridade. Mas quer ir além de seu pai: quer dar afeto e carinho. Isso é o que assume para si como compromisso de paternidade. E ele continua falando...

C: ... Luciana é a mais teimosa. A gente chegou num ponto que ela... quando eu me aproximava da Marta, tipo pra dar um beijo, alguma coisa assim, ela emburrava . . . aí, nesse caso eu cheguei um dia e tive uma conversa com ela, falei: 'Óh! Eu tô te adotando pra ser seu pai e, no relacionamento de pai e filha num existe isso. Então ou acaba isso, porque a gente não vai poder, você ser minha filha e querer procurar esse tipo de contato, esse tipo de coisa não existe!' . . . isso te deixa um pouco armado ... A outra é sem malícia nenhuma . . . A Cristina é totalmente desarmada.

Ainda respondendo sobre como está sendo ser pai naquele momento, Cristiano fala da sexualidade ou malícia de Luciana e relata como resolveu o problema. Sua narrativa mostra como ele vai se posicionando diferentemente em relação às duas meninas, de acordo com o jeito que se percebe sendo posicionado por elas. Assim, ao julgar que Luciana o trata como homem e não como pai, que o procura com desejos e fantasias que para ele não são de menina, ele posiciona-se em relação a ela como um pai que conversa, mas que também ameaça. Relata o seu incômodo com a situação e, nesse momento, o vínculo parece frágil, pois para ele, continuar desse modo, não vai ser possível. Afasta-se e a evita. Esta desconfiança vai marcar a história de interações com ela, criando uma trama de sentidos que parecem ser recorrentes sempre que se refere a ela. Já com Cristina, que ele julga ser sem malícia, assume uma posição de pai acolhedor e carinhoso.

$3^{\mathrm{a}}$. Entrevista (1 ano e 1 mês com as meninas) - Ser pai é muito gratificante, é adorável.

N: E... Cristiano como é que está sendo ser pai?

C: Uai, eu tô gostando, eu sempre quis muito, gosto muito de criança, eu tô... adorando . . . eu acho que a gente parte de um sonho, de um ideal, igual um casamento, você sai do ideal pro real. Aí você vai ter que tá ajustando, você fala: 'Pô, mas aquela menininha que eu sonhava, mas ela não faz isso, faz aquilo, e a outra é desse jeito e...', mas tudo é muito gratificante com a convivência, porque você faz pra elas o que elas fazem pra você também. Mesmo a Luciana, que até agora só falei dos problemas, mas lógico que tem um monte de coisa boa que ela trás, você vê ela aprendendo, ela faz uma coisa errada, eu reprimo e a partir dali ela não faz mais. Eu acho que ela tem vontade de melhorar. Eu gosto disso da gente tá podendo moldar, tá podendo criar essa personalidade dela, no sentido de ajudar e de ser essa família que a gente tem hoje.

Cristiano na terceira entrevista posiciona-se como alguém que está adorando ser pai. Sente-se gratificado com a experiência cotidiana com as crianças e, nesse momento, muda seu posicionamento em relação à Luciana valorizando seu empenho em melhorar. Segundo ele, no plano real e não ideal, as relações precisam de ajustes, talvez por isso seja possível ter, após um ano da adoção, uma avaliação da paternidade como gratificante, visto que as meninas mudaram muito e se adequaram aos limites que ele e Marta colocaram. Cristiano se sente cumprindo seu papel de pai ao moldar e criar uma personalidade, especialmente de Luciana. Ser pai para Cristiano significa que ele constituiu uma família, sua realização. E isso foi possível porque as meninas abandonaram alguns hábitos, aceitaram seus limites.

\section{Considerações Finais}

Limbo. 1. Orla, borda . . 4. Rel. Lugar onde, segundo a teologia católica posterior ao séc. XIII, se encontram as almas das crianças muito novas que, embora não tivessem alguma culpa pessoal, morreram sem o batismo que as livrasse do pecado original. (Ferreira, 1988, p. 394).

Ao refletirmos sobre os sentidos de maternidade e paternidade apresentados neste artigo, é importante considerar que a filiação por adoção traz especificidades não presentes na filiação biológica. O processo de Marta e Cristiano se caracteriza como um tornar-se pai e mãe dentro de um período de guarda provisória, em uma adoção tardia e de grupo de irmãos. Um período de limbo, frágil, em que se negociam e se constroem vínculos de maternidade, paternidade e filiação, onde todos os envolvidos sabem da possibilidade da devolução.

Levy-Shiff e Har-Even (1991), em pesquisa desenvolvida com pais adotivos e biológicos, argumentam que a transição para a parentalidade na adoção tende a ser abrupta, sem um envolvimento gradual dos pais com seus papéis parentais e, por isso, os pais adotivos tendem a ter mais dificuldades e passam por maiores tensões que os pais biológicos. Essas mudanças são abruptas nas relações sociais, pois muitos pais ainda enfrentam o estigma associado à adoção e atitudes negativas fundamentadas em concepções que valorizam a fecundidade e laços consangüíneos. Weir (2003) reforça esse aspecto da transição rápida para a parentalidade nas famílias adotivas e argumenta que esse processo tende a ser mais estressante, pelas múltiplas escolhas que elas têm que fazer, sendo mais complexo e multidimensional que para pais biológicos.

$\mathrm{Na}$ adoção tardia a tensão é ainda mais complexa porque a criança se posiciona no processo interativo de modo mais ativo que um bebê, aceitando, negando e negociando posições que lhe são atribuídas, somado ao fato de que ela tem uma história pregressa. Uma história de vida anterior às relações agora estabelecidas.

Existem argumentações de que o tempo de guarda provisória não deve ser apressado em casos de adoções tardias (Andrei, 2001), de modo a favorecer o tempo de namoro com a criança e um conhecimento mútuo entre pais e crianças. Entretanto, cabe perguntar se os envolvidos na situação não permanecem no limbo. É inegável que uma 
sentença do juiz favorável à adoção traria um outro status a essas crianças e pais. Nesse limbo, Marta e Cristiano passam por momentos em que se perguntam se são pais ou não dessas crianças, assim como Luciana e Cristina também passam por dúvidas. E o processo jurídico não concluído constitui um forte circunscritor dos sentidos de maternidade e paternidade possíveis de serem vivenciados nessa família. As identidades em construção de pai, mãe e filhas ficam ameaçadas ou abaladas pela prorrogação desse período de limbo.

A construção de relações de parentalidade passa por momentos de identificação e estranhamento, que podem ser tensos, e que identificamos no processo de Marta e Cristiano (a devolução aparece quando a relação chega num nível de tensão de ruptura). Talvez, uma dificuldade no estabelecimento desses vínculos está na suposição de que os vínculos de consangüinidade (vínculos de sangue) predominam e são mais fortes que os vínculos pela aliança (como casamento e adoção).

Vale ainda ressaltar que existem poucos trabalhos que abordam a adoção tardia de grupos de irmãos, mas Housset (2001) afirma ser esse um processo que exige dos pais adotivos paciência, perseverança e sensibilidade para responder às necessidades pouco conhecidas de crianças em diferentes idades. Os irmãos tendem a ser muito unidos, sendo que os maiores podem ter assumido em suas histórias anteriores o papel de pais e protetores dos irmãos mais novos. Já os menores podem se expressar menos e, por isso, serem menos ouvidos. Assim, a solidariedade entre os irmãos é valorizada pela autora como um fator importante na integração à nova família.

Outra questão a se considerar, que se apresenta como um complicador no processo de Marta e Cristiano em tornarem-se mãe e pai de Luciana e Cristina, parece ser o fato de eles saberem pouco sobre o passado delas. O conhecimento do passado da criança (seja na instituição ou na família de origem) ajuda os pais adotivos a acolhê-la. É importante que eles tenham informações sobre suas rotinas, gostos, histórias, o que favorece conhecer mais a criança, torná-la familiar, como em qualquer processo de adoção afetiva que fazemos (como num namoro ou ao estabelecer uma amizade). Segundo Brodzinsky et al. (1998), os operadores da adoção precisam fornecer aos pais adotivos informações detalhadas sobre a criança, como seus horários e hábitos, vocabulário (palavras que usam para descrever coisas e lugares) e nomes de pessoas que foram importantes para ela.

Além disso, os pais devem favorecer oportunidades de conversa com a criança sobre seu passado, de modo aberto e não defensivo, auxiliando-a a construir narrativas sobre ele e a não se sentir traindo nem os pais biológicos nem os pais atuais. Desta forma, a criança preenche lacunas de tempo ou de situações não compreendidas, com o auxílio de pessoas significativas para ela e afetivamente envolvidas com o seu bem estar (Brodzinsky et al., 1995; Brodzinsky et al., 1998). Daí a importância, mesmo em uma adoção tardia, em que a criança sabe que é adotada, de se conversar sobre seu passado. Ela não precisa da revelação da adoção, mas provavelmente terá dúvidas sobre o motivo de ter sido retirada da família de origem e entregue para adoção, dentre outros assuntos que são peculiares a cada história. Além disso, Vargas (1998) aponta que as crianças institucionalizadas têm vínculos no abrigo com outras crianças e que elas podem sofrer ao afastarem-se de seus amigos, ou sentirem-se culpadas "ao achar que, ao ter sido escolhida, os outros foram mais uma vez rejeitados ou esquecidos" (p. 145).

Entretanto, parece haver um forte desejo de todos os envolvidos em um processo de adoção (pais adotivos, técnicos) de que o passado da criança seja esquecido, dado que, para a maioria das crianças abrigadas, esse passado envolve histórias de abandono, negligência, rupturas, perdas e (ou) violência. Seria a possibilidade de sair do limbo e ganhar um batismo, uma vida nova. Porém, tais sentidos atribuídos ao passado da criança dificul tam o processo de adoção e de constituição de maternidade e paternidade. Além disso, podem favorecer o segredo em torno da adoção para aquelas crianças adotadas mais novas e que vão precisar de uma revelação ou, nas adoções tardias, podem desenvolver um sentimento de que é proibido falar desse passado ruim (interdição).

Por outro lado, o desejo de sair da situação de ser mãe ou pai (devolução) também é relatado por mães e pais biológicos. Essa tensão entre adoção afetiva e não adoção parece ser constitutiva das relações entre pais e filhos, embora no contexto de filiação adotiva se estabeleçam poderes diferentes de negociação.

Finalizando, cabe ainda ressaltar a importância dos acompanhamentos de pré e pós-adoção, no sentido de se discutir com os candidatos à adoção questões relativas à parentalidade adotiva e, feita a adoção, favorecer o envolvimento afetivo dos pais com a criança. Nesse ponto, apenas fazemos coro ao que vem sendo enfaticamente argumentado tanto pela literatura internacional, quanto pela nacional.

\section{Referências}

Andrei, D. (2001). Reflexões sobre a adoção tardia. In F. Freire (Ed.), Abandono e adoção. Contribuições para uma cultura da adoção III (pp. 91-98). Curitiba, PR: Terra dos Homens.

Brodzinsky, D. M., Lang, R., \& Smith, D. W. (1995). Parenting adopted children. In M. H. Bornstein (Ed.), Handbook of parenting (pp. 209-232). Mahwah, NJ: Lawrence Erlbaum.

Brodzinsky, D. M., Smith, D. W., \& Brodzinsky, A. B. (1998). Children's adjustment to adoption. Thousand Oaks, CA: Sage.

Cassin, W. (2000). O psicólogo judiciário e a cultura da adoção: Limites, contradições e perspectivas. Disser tação de Mestrado nãopublicada, Curso de Pós-Graduação em Psicologia, Universidade de São Paulo, Ribeirão Preto, SP.

Ebrahim, S. G. (2001). Adoção tardia: Altruísmo, maturidade e estabilidade emocional. Psicologia: Reflexão e Crítica, 14(1), $73-80$

Ferreira, A. B. H. (1988). Novo Dicionário Aurélio da Lingua Portuguesa. Rio de Janeiro, RJ: Nova Fronteira. 
Fonseca, C. (1999). Quando cada caso não é um caso. Pesquisa etnográfica e educação. Revista Brasileira de Educação, $10,58-78$.

Freire, F. (2001). Abandono e adoção. Contribuições para uma cultura da adoção III. Curitiba, PR: Terra dos Homens.

Gailey, C. W. (2000). Ideologies of motherhood and kinship in US adoption. In H. Ragoné \& F. Twine (Eds.), Ideologies of motherhood (pp. 11-55). New York: Routledge.

Granato, E. F. R. (2003). Adoção: Doutrina e prática. Curitiba, PR: Juruá.

Housset, D. (2001). Adoção de irmãos. In F. Freire (Ed.), Abandono e adoção. Contribuições para uma cultura da adoção III (pp. 119-126). Curitiba, PR: Terra dos Homens.

Levy-Shiff, I. G., \& Har-Even, D. (1991). Transitions to parenthood in adoptive families. Developmental Psychology, 27(1), 131-140.

Mariano, F. N. (2004). O cenário jurídico: A análise de processos de adoção no município de Ribeirão Preto (1991-200o). Dissertação de Mestrado não-publicada, Curso de Pós-Graduação em Psicologia, Universidade de São Paulo, Ribeirão Preto, SP.

Palacios, J., \& Amorós, P. (2006). Recent changes in adoption and fostering in Spain. British Journal of Social Work, 17, 115.

Palacios, J., Sandoval, Y. S., \& Espinosa, E. M. S. (1996). La adopción en Andalucía. Sevilla, España: Junta de Andalucía / Consejería de Asuntos Sociales.

Pereira, T. S. (1996). Direito da criança e do adolescente: Uma proposta interdisciplinar. Rio de Janeiro, RJ: Renovar.

Prynn, B. (2001). Family building in adoption. Adoption $\&$ Fostering, 25(1), 33-43.

Rossetti-Ferreira, M. C., Amorim, K. S., Silva, A. P. S., \& Carvalho, A. M. A. (2004). Rede de Significações e o estudo do desenvolvimento humano. Porto Alegre, RS: Artmed.

Rushton, A. (2003). Support for adoptive families. A review of current evidence on problems, needs and effectiveness. Adoption \& Fostering, 27(3), 41-50.

Spink, M. J. (1999). Práticas discursivas e produção de sentidos no cotidiano. São Paulo, SP: Cortez.

Trindade, Z. A. (1993). As representações sociais e o cotidiano: A questão da maternidade e da paternidade. Psicologia: Teoria e Pesquisa, 9(3), 535-546.

Vargas, M. (1998). Adoção tardia: Da família sonhada à família possivel. São Paulo, SP: Casa do Psicólogo.

Weber, L. (2003). Pais e filhos por adoção no Brasil. Curitiba, PR: Juruá.

Weir, K. (2003). Adoptive family «leap-frogging» patterns. Adoption Quarterly, 7(1), 27-41.

Wegar, K. (1997). In search of bad mothers: social constructions of birth and adoptive motherhood. Women's Studies International Forum, 2O(1), 77-86. 